OPEN ACCESS

Edited by:

Sitesh C. Bachar,

University of Dhaka, Bangladesh

Reviewed by:

Kishor Mazumder,

Jashore University of Science and

Technology, Bangladesh

Asish Das,

Khulna University, Bangladesh

*Correspondence:

Rawiwan Charoensup

rawiwan.cha@mfu.ac.th

Specialty section: This article was submitted to

Ethnopharmacology,

a section of the journal

Frontiers in Pharmacology

Received: 18 October 2021 Accepted: 04 February 2022

Published: 07 March 2022

Citation:

Rujanapun N, Jaidee W, Duangyod T,

Phuneerub $P$, Paojumroom $N$, Maneerat T, Pringpuangkeo C, Ramli S and Charoensup $R$ (2022) Special Thai

Oolong Tea: Chemical Profile and In

Vitro Antidiabetic Activities.

Front. Pharmacol. 13:797032

doi: 10.3389/fphar.2022.797032

\section{Special Thai Oolong Tea: Chemical Profile and In Vitro Antidiabetic Activities}

\author{
Narawadee Rujanapun ${ }^{1}$, Wuttichai Jaidee ${ }^{1}$, Thidarat Duangyod ${ }^{1,2}$, Pravaree Phuneerub ${ }^{1,2}$, \\ Napassawan Paojumroom ${ }^{1}$, Tharakorn Maneerat ${ }^{1,3}$, Chuchawal Pringpuangkeo ${ }^{4}$, \\ Salfarina Ramli ${ }^{5,6}$ and Rawiwan Charoensup ${ }^{1,2 *}$
}

${ }^{1}$ Medicinal Plant Innovation Center of Mae Fah Luang University, Mae Fah Luang University, Chiang Rai, Thailand, ${ }^{2}$ School of Integrative Medicine, Mae Fah Luang University, Chiang Rai, Thailand, ${ }^{3}$ Center of Chemical Innovation for Sustainability, School of Science, Mae Fah Luang University, Chiang Rai, Thailand, ${ }^{4}$ Doi Chang Tea Co., Ltd., Mae Lao, Thailand, ${ }^{5}$ Faculty of Pharmacy, Universiti Teknologi MARA Cawangan Selangor, Selangor, Malaysia, ${ }^{6}$ Interactive Pharmacogenomics Institute (iPROMISE), Universiti Teknologi MARA Cawangan Selangor, Selangor, Malaysia

Special Thai oolong tea is oolong tea (Camellia sinensis (L.) Kuntze) steamed with selected Thai botanical drugs. Oolong tea steamed with ginger (Zingiber officinale), lemongrass (Cymbopogon citratus), and celery (Anathallis graveolens L.) is called eternity tea (EN), whereas peaceful rest (PR) tea is made of oolong tea leaves steamed with Indian gooseberry (Phyllanthus emblica), Turkey berry (Solanum torvum), and wild betel leaf bush leaves (Piper sarmentosum). Oolong tea is known for its numerous biological activities including antidiabetic properties. However, the effect of the additional botanical drugs on the biological activities of special oolong teas has not yet been explored. From the results, the PR extract exhibited the best activity in the in vitro assays relevant to antidiabetic properties such as chemical antioxidant, antiinflammation, anti-adipogenesis, enzyme inhibition, and glucose uptake and consumption. The UHPLC-QTOF-MS/MS profiles of PR and EN extracts indicated chemical profiles different from oolong tea. For instance, gingerdiol and gingerol were detected in EN, whereas piperettine I was detected in PR. Therefore, it was inferred that among the three tea extracts, the additional compounds in PR contributed to good activities compared to oolong and EN. It is also important to highlight that the PR extract inhibited glucose uptake and consumption by adipocytes and skeletal muscles at concentrations of 500 and $100 \mu \mathrm{g} / \mathrm{ml}$, respectively, as well as metformin activity $(p<$ 0.05). Findings from this study support the antidiabetic potential of PR tea.

Keywords: peaceful rest tea, eternity tea, oolong teas, hyperglycemia, Thai botanical drug, antidiabetic

\section{INTRODUCTION}

Globally, the incidence of unhealthy lifestyle-derived diseases such as type 2 diabetes (T2D) and cardiovascular diseases has increased yearly. Uncontrolled hyperglycemia is a major cause of blindness, kidney failure, and lower limb amputation, whereas the unnecessary expansion of adipose tissue causes metabolic disorders such as insulin resistance, dyslipidemia, and hypertension. Without proper interventions, it is anticipated that this situation may lead to the growing death rate and health burden due to diabetes in the year 2025 (Lin et al., 2020). T2D is a 
complex multifactorial disease resulting from the imbalance of sugar homeostasis. High blood sugar or hyperglycemia could result from insulin resistance or pancreatic cells not producing enough insulin to accommodate the sugar level in the blood. Consequently, the impaired glucose homeostasis led to free radical production and inflammation. Pathophysiological pathways associated with oxidative stress and inflammation in diabetes mellitus indicate the progress of the disease (Lima et al., 2021).

Regular exercise and healthy diet have been suggested as able to control the progression of diabetes and cardiovascular diseases. Furthermore, regular intake of beverages such as cocoa, wine, and tea confers health-protective effects due to their antihyperglycemic, enzyme-inhibiting, antioxidant, and antiinflammatory properties (Martin et al., 2017; Sun et al., 2020).

The intake of oolong [Camellia sinensis (L.) Kuntze] tea is popular for preventing obesity and improving lipid metabolism, as demonstrated by their ability to lower total cholesterol and plasma triglyceride levels, along with the reduction in blood pressure and platelet aggregation activity (He et al., 2013). Other reported pharmacological activities of oolong tea and its bioactive compound theasinensins are anticancer, antioxidant, and antimicrobial activities (Zhang et al., 2019).

Infusing medicinal plants such as ginger (Zingiber officinale Roscoe) or cloves (Syzygium aromaticum (L.) Merr. and L.M.Perry) in tea has been a beneficial common practice. For instance, green tea extracts enriched with natural components like mint, cloves, and ginger in combination improved the efficacy level of treating oral infections (Somasundaram et al., 2019).

Previously, a study reported the antioxidant and anti-glycation activities of 15 Thai botanical drug teas, including lemongrass (Cymbopogon citratus (DC.) Stapf), mulberry (Morus alba L.), and betel leaves (Piper sarmentosum Roxb.). However, their antioxidants and anti-glycation activities were low compared to green tea, oolong tea, and black tea (Deetae et al., 2012). Nevertheless, it is intriguing to combine tea and Thai botanical drugs into one special tea and explore the biological activities.

In this study, "special Thai oolong tea" is an oolong tea steamed with select Thai botanical drug water extracts. Eternity tea (EN) is made of dried oolong tea leaves steamed with ginger (Zingiber officinale Roscoe), lemongrass (Cymbopogon citratus (DC.) Stapf), and celery (Anathallis graveolens (Pabst) F. Barros) water extracts, while peaceful rest tea (PR) is made of oolong tea leaves steamed with Indian gooseberry (Phyllanthus emblica L.), Turkey berry (Solanum torvum Sw.), and wild betel leaf bush (Piper sarmentosum Roxb.) leaf water extracts.

The aim of the study was to investigate the antidiabetic properties of EN and PR with oolong tea using in vitro assays. The total phenolic content and chemical antioxidant assays were also carried out. Additionally, the chemical profiles of EN, PR, and oolong tea extracts were analyzed using the UHPLC-QTOF-MS to investigate the presence of phytochemicals from the botanical drugs in the special oolong tea extracts.

\section{MATERIALS AND METHODS}

\section{Plant Sample Material}

All tea products, including eternity tea $(\mathrm{EN})$, peaceful rest tea (PR), and oolong tea, were obtained from the Doi Chang organic tea plantation in Chiang Rai, Thailand. EN tea was prepared by steaming dried oolong tea leaves $(2 \mathrm{~kg})$ with ginger $(2 \mathrm{~kg})$, lemongrass $(2 \mathrm{~kg})$, and celery $(0.4 \mathrm{~kg})$ for $30 \mathrm{~min}$, whereas PR tea comprises oolong tea leaves $(5 \mathrm{~kg})$ steamed with Indian gooseberry $(2 \mathrm{~kg})$, turkey berry ( $1 \mathrm{~kg})$, and wild betel leaf bush leaves $(0.4 \mathrm{~kg})$ for $30 \mathrm{~min}$. Next, streamed tea was incubated at $80^{\circ} \mathrm{C}$ for $2 \mathrm{~h}$. Voucher specimens of these samples were authenticated by Charoensup $\mathrm{R}$ and Pringpuangkeo C. and deposited at the Medicinal Plant Innovation Center of Mae Fah Luang University, Thailand.

\section{Preparation of Water Extract}

Each tea sample was extracted with water at $95^{\circ} \mathrm{C}$ for $30 \mathrm{~min}$ and freeze-dried to provide water extracts.

\section{Inhibition of $\alpha$-Glucosidase and $\alpha$-Amylase Enzymes}

Tea extracts were determined at concentrations of $0.04,0.2,2,4$, and $12 \mu \mathrm{g} / \mathrm{ml}$. Fifty microliters of tea extracts were mixed with $100 \mu \mathrm{L}$ of $a$-glucosidase $(0.35 \mathrm{U} / \mathrm{mL})$ (CAS: $9001-42-7)$ and incubated at $37^{\circ} \mathrm{C}$. After $10 \mathrm{~min}, 100 \mu \mathrm{L}$ of $p$-NPG $(1.5 \mathrm{mM})$ (CAS: 2492-87-7) was added to the mixture and incubated at $37^{\circ} \mathrm{C}$ for $20 \mathrm{~min}$. The reaction was terminated by the addition of $1,000 \mu \mathrm{L}$ of $\mathrm{Na}_{2} \mathrm{CO}_{3}$. Two hundred microliters of the mixture was measured at $405 \mathrm{~nm}$ on a microplate reader. Acarbose (CAS: 56180-94-0) was used as a positive control for the a-glucosidase inhibitor. The $\mathrm{IC}_{50}$ value was calculated (Striegel et al., 2015). For $\alpha$-amylase inhibition activity, tea extract concentrations of 0.027 , $0.055,0.27,0.55,2.77$, and $27.77 \mu \mathrm{g} / \mathrm{ml}$ were tested. Acarbose was used as a positive control. Sixty microliters of tea extract/control solution was mixed with $120 \mu \mathrm{L}$ of starch solution and incubated at $37^{\circ} \mathrm{C}$ for $10 \mathrm{~min}$. Then, $180 \mu \mathrm{L}$ of $\alpha$-amylase $(1 \mathrm{U} / \mathrm{mL}$ ) (EC no: 232-588-1) was added to the solution and incubated for $30 \mathrm{~min}$. The reaction was terminated by adding $240 \mu \mathrm{L}$ of $0.1 \mathrm{M} \mathrm{HCl}$ (CAS: $7647-01-0)$, and then $300 \mu \mathrm{L}$ of $0.1 \mathrm{mM}$ iodine solution (CAS: 7553-56-2) was added. The solution was mixed with $500 \mu \mathrm{L}$ of $0.2 \mathrm{M}$ acetate buffer (CAS: 126-96-5), and the absorbance was measured using a spectrophotometer. The $\mathrm{IC}_{50}$ value was calculated (Kusano et al., 2011).

\section{Glucose Consumption by Adipocytes and Skeletal Muscle Assay}

The Zhang method was used for glucose consumption measurement. The 3T3-L1 preadipocyte cell $\left(\mathrm{ATcc}^{\circledR} \mathrm{cL}-173^{\mathrm{TM}}\right.$ ) density was adjusted to a concentration of $1 \times 10^{5}$ cells $/ \mathrm{mL}$, and cells were spread onto 96 -well microtiter plates $(100 \mu \mathrm{L}$ per well). The cells were cultured with a serial concentration of extracts including $25,50,100,250$, and $500 \mu \mathrm{g} / \mathrm{ml}$ for $24 \mathrm{~h}$. Insulin (CAS: 11061-68-0) and metformin (CAS: 1115-70-4) were used as 
TABLE $1 \mid \alpha$-Glucosidase and $\alpha$-amylase inhibition assay.

\begin{tabular}{lcc}
\hline Tea extract & \multicolumn{2}{c}{$\mathbf{I C}_{\mathbf{5 0}}(\boldsymbol{\mu} \mathbf{g} / \mathbf{m l})$} \\
\cline { 2 - 3 } & $\boldsymbol{\alpha}$-Glucosidase & $\boldsymbol{\alpha}$-Amylase \\
\hline PR & $1.22 \pm 0.05^{\mathrm{d}}$ & $<0.03^{\mathrm{C}}$ \\
EN & $3.50 \pm 0.03^{\mathrm{b}}$ & $1.73 \pm 0.23^{\mathrm{b}}$ \\
Oolong & $1.48 \pm 0.004^{\mathrm{C}}$ & $<0.03^{\mathrm{c}}$ \\
Acarbose & $75.71 \pm 0.34^{\mathrm{a}}$ & $28.73 \pm 1.28^{\mathrm{a}}$
\end{tabular}

Data are represented as mean \pm standard deviation $(S D) . p \leq 0.05$ is statistically significant. PR, peaceful rest tea; EN, eternity tea.

positive controls at concentrations of 1 and $755 \mu \mathrm{M}$, respectively. At the end of incubation, $10 \mu \mathrm{L}$ of suspension or glucose (CAS: 50-99-7) standard medium (0-1000 mg/L) was measured for the glucose oxidase-peroxidase (GOD-POD) assay (Zhang et al., 2008). For sugar uptake by skeletal muscle cells, the experiments were initiated on day 7 when the differentiation of L6 myoblast cells (ATcc ${ }^{\circledR}$ CRL-1458 ${ }^{\mathrm{TM}}$ ) to a myotube was completed. Next, cells were incubated with tea extracts or metformin for $24 \mathrm{~h}$. Cells were washed with Krebs-Ringer bicarbonate buffer twice, incubated with Krebs-Ringer bicarbonate buffer for $1 \mathrm{~h}$, and starved in serum-free PBS containing $0.2 \% \mathrm{c}$ for $1 \mathrm{~h}$. After incubation, the cells were incubated with 2-NBDG (CAS: 186689-07-6) for $20 \mathrm{~min}$ minutes. The samples demonstrated fluorescence intensity at an excitation/emission of 485/530 nm (Yamamoto et al., 2015).

\section{Anti-Adipogenesis Assay}

The 3T3-L1 preadipocyte cell lines were treated with $50 \mu \mathrm{g} / \mathrm{ml}$ tea extracts and metformin, which were cultured in DMEM supplemented with $1 \mu \mathrm{M}$ dexamethasone (CAS: 50-02-2), $10 \mu \mathrm{g} / \mathrm{ml}$ insulin, and $0.5 \mathrm{mM}$ 3-isobutyl-1-methylxanthine (IBMX) (CAS: 28822-58-4), for 2 days. After 2 days, the medium was changed to DMEM containing $10 \mu \mathrm{g} / \mathrm{ml}$ insulin for 2 days. At the end of incubation, the medium was changed to DMEM until day 10. Lipid accumulation was assessed using oil red O staining (CAS: 1320-06-5). The samples were observed and recorded under a microscope. After that, the cells were dissolved in DMSO (CAS: 67-68-5), and the absorbance was measured at $510 \mathrm{~nm}$ (Cheng et al., 2006; Bunkrongcheap et al., 2014).

\section{Viability Assay Using RAW 264.7 and K562 Cells}

The cytotoxicity was determined with MTT assay. RAW 264.7 $\left(\mathrm{ATcc}^{\circledR} \mathrm{TIB}-71^{\mathrm{TM}}\right.$ ) cells and K562 lymphoblastoid human erythroleukemia cell line $\left(\mathrm{ATcc}{ }^{\circledR} \mathrm{CRL}-3343^{\mathrm{TM}}\right.$ ) were seeded at $4 \times 10^{4}$ cells/well in 96-well plates were treated with different concentrations of tea extracts $(6.25,12.5,25,50,100,250$, and $500 \mu \mathrm{g} / \mathrm{ml}$ ), for $24 \mathrm{~h}$. Next, the cells were washed with PBS and incubated with $0.5 \mathrm{mM}$ MTT (CAS: 57360-69-7) reagent and $0.15 \mathrm{mg} / \mathrm{ml}$ resazurin (CAS: 62758-13-8), respectively, for $4 \mathrm{~h}$. The detection of viable cells was performed with a microplate reader (Fares et al., 2015; Nam et al., 2017).

\section{Anti-Inflammatory Assay}

RAW 264.7 cells were seeded at $4 \times 10^{4}$ cells/well in 96-well plates, incubated with $1 \mu \mathrm{g} / \mathrm{ml}$ LPS (EC no. 297-473-0) for $1 \mathrm{~h}$, and treated with various concentrations of tea extract, including $6.25,12.5,25,50$, and $100 \mu \mathrm{g} / \mathrm{ml}$, for $24 \mathrm{~h}$. NO production was measured using Griess reagent (EC no. 215-981-2). The data were presented as the $\mathrm{IC}_{50}$ (Kang et al., 2016).

\section{Chemical Antioxidant Assays DPPH Free Radical Scavenging Activity}

The three replications of tea extracts were tested at concentrations of $0.25,0.5,1.25$, and $2.5 \mu \mathrm{g} / \mathrm{ml}$. Five hundred microliters of tea extract solution was mixed with $500 \mu \mathrm{L}$ of $59 \mu \mathrm{M}$ DPPH solution (CAS 1898-66-4) in methanol (CAS 67-56-1). (+)-Catechin hydrate (CAS No- 154-23-4) was used as a positive control, and triplicate measurements were carried out. Next, the $\mathrm{IC}_{50}$ was calculated (Duangyod et al., 2015).

\section{ABTS Free Radical Scavenging Activity}

The photometric assay was conducted on a mixture of $500 \mu \mathrm{L}$ of ABTS solution (CAS:30931-67-0) and $500 \mu \mathrm{L}$ of tea extract (0.5, $1.25,2.5,3.5$, and $5 \mu \mathrm{g} / \mathrm{ml})$. (+)-Catechin hydrate was used as a

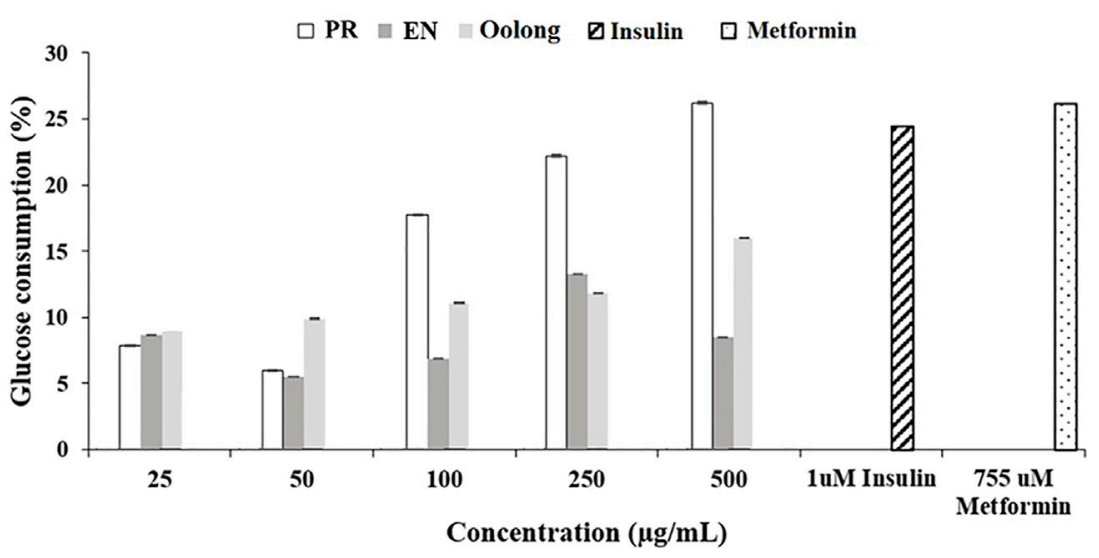

FIGURE 1 | Effect of tea water extracts on glucose consumption in 3T3-L1 cells. PR, peaceful rest tea; EN, eternity tea. 


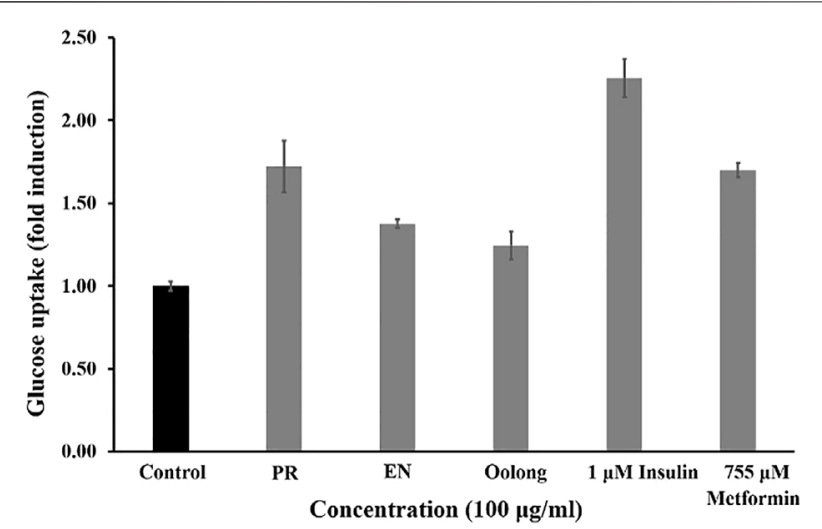

FIGURE 2 | Effect of PR, EN, and oolong tea water extracts at concentration of $100 \mu \mathrm{g} / \mathrm{ml}$ on glucose uptake in L6 cells. PR, peaceful rest tea; EN, eternity tea.

positive control, and triplicate measurements were carried out. The percentage of scavenging activity and $\mathrm{IC}_{50}$ was calculated (Duangyod et al., 2015).

\section{Total Phenolic Content}

The total phenolic content was determined following the Duangyod study. In total, $800 \mu \mathrm{L}$ of sample extracts at $1 \mathrm{mg}$ / ml concentration and $200 \mu \mathrm{L}$ of $15 \%$ Folin-Ciocalteu reagent (CAS:12,111-13-6) were added to the test tube, and the volume was adjusted to $2.0 \mathrm{ml}$ with water. The mixture was left for 5 mins. Next, $1.0 \mathrm{ml}$ of $\mathrm{Na}_{2} \mathrm{CO}_{3}(0.106 \mathrm{~g} / \mathrm{ml})$ (CAS: 497-19-8) was added. The mixture was kept in the dark at room temperature for $60 \mathrm{~min}$. The absorbance was measured at $756 \mathrm{~nm}$. The total phenolic content of the tea extracts was determined through a linear gallic acid standard curve and expressed as milligrams of gallic acid equivalents (GAE) (CAS: 497-19-7) per gram of dry extract (Duangyod et al., 2015).

\section{UltraHigh-Performance Liquid Chromatography Quadrupole} Time-of-Flight Mass Spectrometry Analysis An Agilent 6500 Series LC Q-TOF System with a column (C-18 $\left.2.1^{\star} 50 \mathrm{~mm}, 1.7 \mu \mathrm{m}\right)$ from Zorbax Eclipse Plus was utilized. The mobile phase was composed of solvent $\mathrm{A}: \mathrm{H}_{2} \mathrm{O}+0.1 \%$ formic acid and solvent $\mathrm{B}: \mathrm{ACN}+0.1 \%$ formic acid. The flow rate was $400 \mu \mathrm{L} /$ min. The elution was performed starting at $5 \% \mathrm{~B}$, which was linearly increased to $95 \% \mathrm{~B}$ in $1 \mathrm{~min}$, after which a linear gradient was applied to $17 \% \mathrm{~B}$ in $13 \mathrm{~min}$ and $100 \% \mathrm{~B}$ in $22 \mathrm{~min}$. The injection volume was $1.0 \mu \mathrm{L}$ for the measurements in both positive and negative modes. The instrument parameters were a gas temperature of $350^{\circ} \mathrm{C}$, a gas flow of $13 \mathrm{~L} / \mathrm{min}$, and a nebulizer pressure of 45 psig. Agilent Mass Hunter Qualitative Analysis Software, version 8.00, was used for the initial processing of the LC/MS data. Compounds were revealed using the Molecular Feature Extractor (MFE) tool in the software. Mass Hunter Profiler Professional (MPP), version 15.1, was used for statistical analysis to profile the samples, such as principal

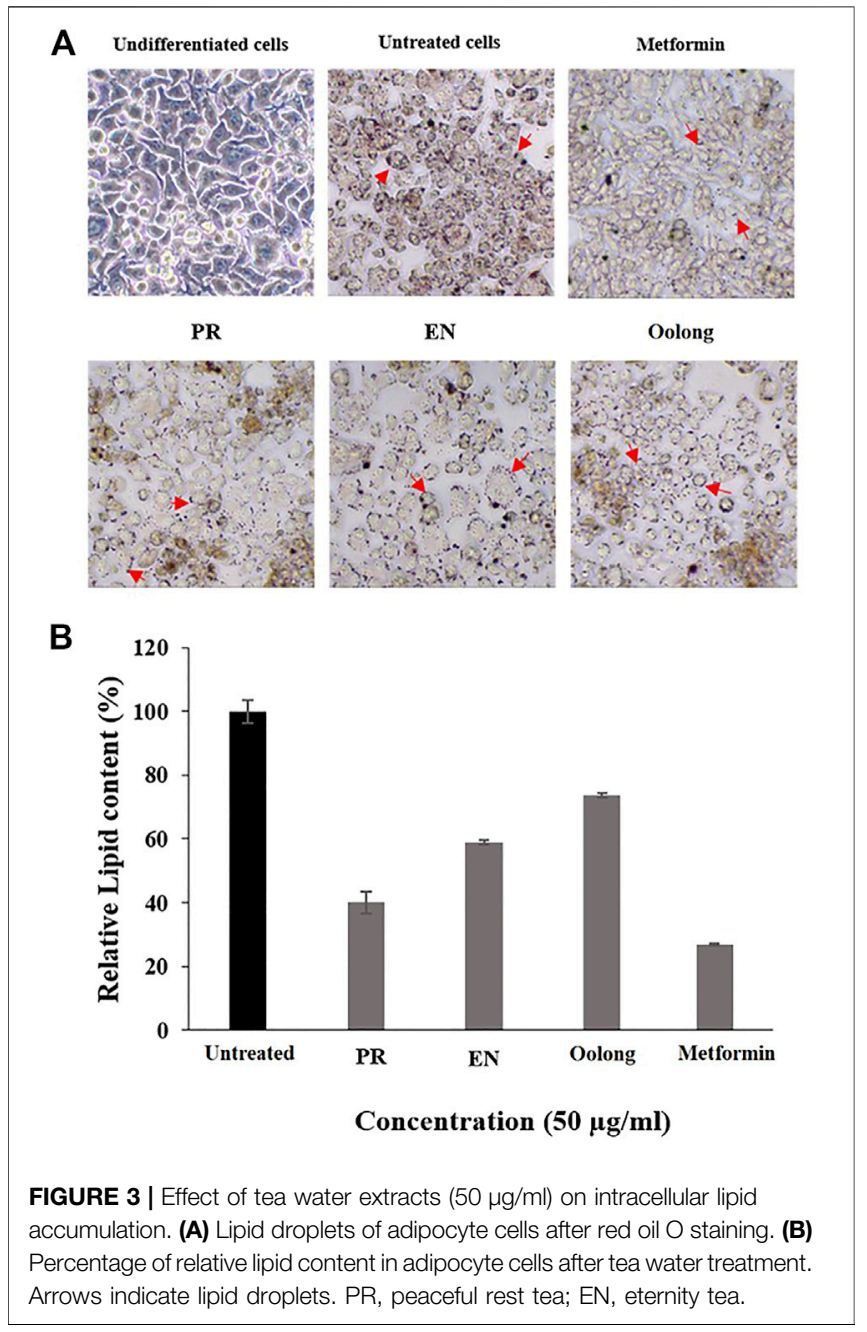

component analysis (PCA). The identification of the peaks was made based on retention time, the analysis of precursor ions, adduct, and error.

\section{Statistical Analysis}

Statistical analysis was performed using SPSS 12.0 software for Windows. Means between the control and treated groups were compared and analyzed using one-way analysis of variance (ANOVA), followed by Tukey's post hoc test. The value of $p<0.05$ was considered statistically significant.

\section{RESULTS AND DISCUSSION}

In this study, the chemical profiles and antidiabetic properties of oolong tea and special oolong teas, PR and EN, were evaluated by in vitro assays. The properties of the tea extracts were compared with the activities of antidiabetic drugs; acarbose, metformin, and insulin. Hyperglycemia is a serious problem for diabetic patients; therefore, inhibiting $\alpha$-amylase and $\alpha$-glucosidase enzymes is useful for the control of hyperglycemia. By inhibiting the enzymes from hydrolyzing carbohydrates to simple sugar, the 


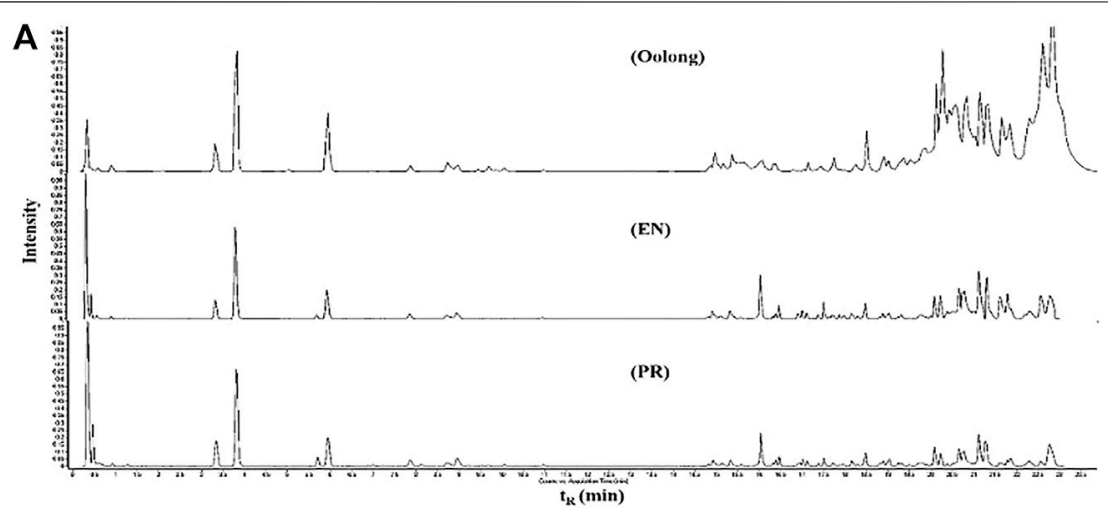

B

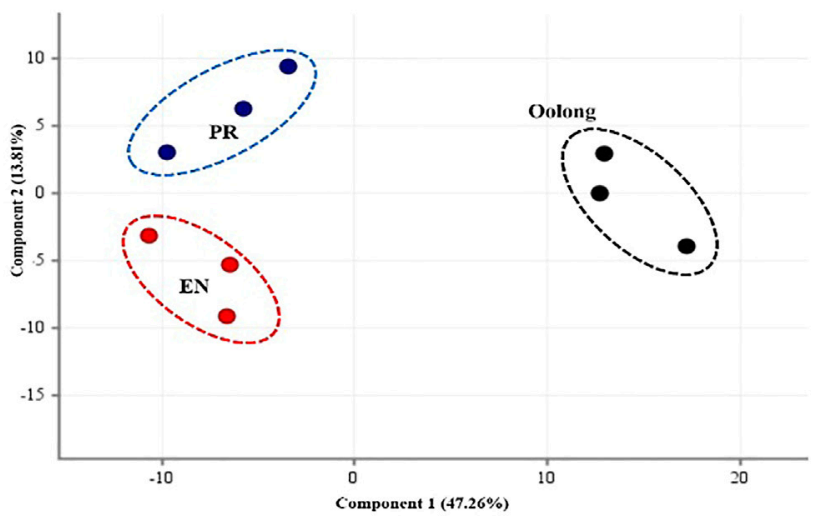

FIGURE 4 | Chemical profile of tea extracts. (A) Total ion chromatogram of oolong, EN, and PR. (B) Score plot PCA of the chemical compounds from oolong, EN, and PR. RT, retention time; PR, peaceful rest tea; EN, eternity tea.

TABLE 2 | Antioxidant activities and total phenolic content of tea extracts.

\begin{tabular}{|c|c|c|c|}
\hline \multirow[t]{3}{*}{ Tea extract } & \multicolumn{2}{|c|}{ Antioxidant } & \multirow{3}{*}{$\frac{\text { Total phenolic content }}{(\mu \mathrm{g} \mathrm{GAE} / \mathrm{mg})}$} \\
\hline & \multicolumn{2}{|c|}{$\mathrm{IC}_{50}(\mu \mathrm{g} / \mathrm{ml})$} & \\
\hline & DPPH & ABTS & \\
\hline PR & $1.84 \pm 0.02^{b}$ & $2.37 \pm 0.02^{b}$ & $62.07 \pm 0.0012^{c}$ \\
\hline EN & $2.48 \pm 0.01^{d}$ & $3.12 \pm 0.04^{c}$ & $61.29 \pm 0.0026^{b}$ \\
\hline Oolong & $2.77 \pm 0.00^{c}$ & $3.13 \pm 0.00^{c}$ & $68.37 \pm 0.0021^{a}$ \\
\hline$(+)$-Catechin hydrate & $0.82 \pm 0.04^{a}$ & $0.83 \pm 0.01^{a}$ & - \\
\hline
\end{tabular}

Data are represented as mean \pm standard deviation (SD). $\mathrm{p} \leq 0.05$ is statistically significant. PR, peaceful rest tea; EN, eternity tea; GAE, gallic acid equivalents.

absorption of glucose after food intake can be delayed. From the results, all tea extracts showed $\alpha$-amylase and $\alpha$-glucosidase inhibition activity (Table 1). The $\mathrm{IC}_{50}$ of the extracts was better than that of acarbose. A lower $\mathrm{IC}_{50}$ for $\alpha$-amylase inhibition than $\alpha$-glucosidase by the tea extracts was also noted.

Insulin binding to its receptors enhances glucose transport to skeletal muscle and adipose tissue, which is important for preventing hyperglycemia. Generally, the more glucose is uptaken and consumed by the cells, the less sugar will be available in the blood. As observed in Figure 1, PR extracts affected the cells' glucose consumption in a dose-dependent manner $(50,100,250$, and $500 \mu \mathrm{g} / \mathrm{ml})$, but such pattern was not observed in oolong tea and EN extracts. Treatment with insulin resulted in about $25 \%$ glucose consumption, whereas treatment with $500 \mu \mathrm{g} / \mathrm{ml} \mathrm{PR}$ extracts showed the greatest enhancement of glucose consumption by 3T3-L1 preadipocyte cells. It was noted that the glucose consumption activity of $500 \mu \mathrm{g} / \mathrm{ml}$ PR was not significantly different from that of 755 uM metformin $(p>0.05)$. Next, all tea extracts enhanced glucose uptake in L6 cells compared to the control at a concentration of $100 \mu \mathrm{g} / \mathrm{ml}$ (Figure 2). The glucose uptake was the highest in the L6 cells treated with PR extract, and the activity was not significantly different from $755 \mathrm{uM}$ metformin $(p>0.05)$.

The inhibition of lipid accumulation in cells is essential to prevent insulin resistance in diabetic patients. From the results, the intracellular lipid accumulation in adipocyte cells was reduced by all tea extracts, especially PR extracts, where the least lipid droplets were observed compared to cells treated with EN and oolong tea extracts (Figure 3A). Furthermore, untreated cells showed the highest percentage of relative lipid accumulation (Figure 3B). Metformin induces adipocyte differentiation at low concentrations, while higher concentrations of metformin inhibit adipogenesis via AMPK activation (Chen et al., 2018). Although the PR extract exhibited $40 \%$ of relative lipid content compared to metformin (Figure 3), the percentage is the lowest among other tea extracts.

Inflammation control is important to managing diabetes complications as inflammation also causes insulin resistance 
TABLE 3 | List of compounds tentatively identified in PR tea, EN tea, and oolong tea by UHPLC-QTOF-MS analysis.

\begin{tabular}{|c|c|c|c|c|c|c|}
\hline \multirow[t]{2}{*}{ Compound } & \multirow[t]{2}{*}{ Formula } & \multirow[t]{2}{*}{$m / z$} & \multirow[t]{2}{*}{ Fragment } & \multicolumn{3}{|c|}{ RT (min) } \\
\hline & & & & PR & EN & Oolong \\
\hline Theanine & $\mathrm{C}_{7} \mathrm{H}_{14} \mathrm{~N}_{2} \mathrm{O}_{3}$ & 175.1079 & $140,125,104$ & 0.35 & - & - \\
\hline 6-Hydroxy-7,4-dimethoxyflavone & $\mathrm{C}_{14} \mathrm{H}_{17} \mathrm{O}_{5}$ & 321.1156 & 175,104 & - & 0.35 & - \\
\hline$p$-Coumaric acid & $\mathrm{C}_{9} \mathrm{H}_{8} \mathrm{O}_{3}$ & 182.0812 & 175,104 & - & 0.50 & - \\
\hline Gallocatechin & $\mathrm{C}_{15} \mathrm{H}_{14} \mathrm{O}_{7}$ & 307.0814 & $294,173,139,121$ & 3.33 & 3.34 & 3.35 \\
\hline Caffeine & $\mathrm{C}_{8} \mathrm{H}_{10} \mathrm{~N}_{4} \mathrm{O}_{2}$ & 195.0878 & $195,137,125,121$ & 3.81 & 3.81 & 3.85 \\
\hline Kaempferol 3-O-arabinoside & $\mathrm{C}_{20} \mathrm{H}_{18} \mathrm{O}_{10}$ & 441.1732 & $350,251,171,148$ & 4.84 & - & - \\
\hline Gallocatechin gallate & $\mathrm{C}_{22} \mathrm{H}_{18} \mathrm{O}_{11}$ & 459.0924 & $289,221,139,121$ & - & - & 5.95 \\
\hline Epicatechin-3-gallate & $\mathrm{C}_{22} \mathrm{H}_{18} \mathrm{O}_{11}$ & 459.0923 & $289,221,121$ & - & 5.95 & 5.98 \\
\hline Myricetin 3-galactoside & $\mathrm{C}_{21} \mathrm{H}_{20} \mathrm{O}_{13}$ & 481.2621 & $446,350,251,150$ & 7.87 & - & 7.89 \\
\hline Epiafzelechin & $\mathrm{C}_{15} \mathrm{H}_{14} \mathrm{O}_{5}$ & 275.1869 & $193,185,136,125$ & 8.73 & 8.73 & 8.73 \\
\hline 5-O-Caffeoylquinic acid & $\mathrm{C}_{16} \mathrm{H}_{18} \mathrm{O}_{9}$ & 355.1727 & $221,181,125$ & 9.68 & - & - \\
\hline Myricitrin & $\mathrm{C}_{21} \mathrm{H}_{20} \mathrm{O}_{12}$ & 487.2152 & $398,294,221,181$ & - & 10.47 & - \\
\hline Luteolin-8-C-glucoside & $\mathrm{C}_{21} \mathrm{H}_{19} \mathrm{O}_{11}$ & 448.1009 & $446,320,171$ & - & - & 10.96 \\
\hline Diacetoxy-8-gingerdiol & $\mathrm{C}_{21} \mathrm{H}_{32} \mathrm{O}_{6}$ & 381.1894 & $325,294,227$ & - & 14.99 & - \\
\hline Neopellitorine B & $\mathrm{C}_{15} \mathrm{H}_{25} \mathrm{NO}$ & 236.1621 & $221,181,136$ & 15.47 & - & - \\
\hline Theobromine & $\mathrm{C}_{7} \mathrm{H}_{8} \mathrm{~N}_{4} \mathrm{O}_{2}$ & 203.1049 & 136,110 & 15.59 & - & 15.59 \\
\hline 8-Gingerol & $\mathrm{C}_{19} \mathrm{H}_{30} \mathrm{O}_{4}$ & 323.1468 & $294,262,221,136$ & - & 16.81 & - \\
\hline Catechin & $\mathrm{C}_{15} \mathrm{H}_{14} \mathrm{O}_{6}$ & 291.0864 & 136, 122 & 16.86 & 16.86 & 16.87 \\
\hline Guanosine & $\mathrm{C}_{10} \mathrm{H}_{13} \mathrm{~N}_{5} \mathrm{O}_{5}$ & 284.3312 & $284,262,136,122$ & 17.71 & 17.71 & 17.72 \\
\hline 3-Acetoxy-6-gingerdiol & $\mathrm{C}_{19} \mathrm{H}_{30} \mathrm{O}_{5}$ & 361.2348 & $294,262,136$ & - & 17.97 & - \\
\hline Piperettine I & $\mathrm{C}_{19} \mathrm{H}_{21} \mathrm{NO}_{3}$ & 312.3621 & $301,136,103$ & 18.33 & - & - \\
\hline 3-p-Coumaroylquinic acid & $\mathrm{C}_{16} \mathrm{H}_{18} \mathrm{O}_{8}$ & 361.2347 & $164,144,116$ & - & - & 18.42 \\
\hline 6-Gingerdiol & $\mathrm{C}_{17} \mathrm{H}_{28} \mathrm{O}_{4}$ & 297.2325 & $294,276,150$ & - & 18.87 & - \\
\hline 4-Caffeoylquinic acid & $\mathrm{C}_{16} \mathrm{H}_{18} \mathrm{O}_{9}$ & 355.2817 & $164,136,122$ & - & - & 18.97 \\
\hline 1-Caffeoylquinic acid & $\mathrm{C}_{16} \mathrm{H}_{18} \mathrm{O}_{9}$ & 355.2806 & $164,136,122$ & - & - & 18.97 \\
\hline Kaempferol & $\mathrm{C}_{15} \mathrm{H}_{10} \mathrm{O}_{6}$ & 309.2041 & $262,237,221,185,150$ & 19.02 & 19.02 & - \\
\hline 3-O-methylellagic acid & $\mathrm{C}_{15} \mathrm{H}_{8} \mathrm{O}_{8}$ & 317.17869 & $315,262,229$ & 19.22 & - & - \\
\hline Epicatechin gallate & $\mathrm{C}_{22} \mathrm{H}_{18} \mathrm{O}_{10}$ & 443.3343 & 294, 150, 136 & 19.30 & 19.29 & 19.30 \\
\hline Epicatechin 3-O-(3-O-methyl gallate) & $\mathrm{C}_{23} \mathrm{H}_{20} \mathrm{O}_{10}$ & 457.3509 & $406,294,136,122$ & - & - & 19.80 \\
\hline Theasinensin A & $\mathrm{C}_{44} \mathrm{H}_{34} \mathrm{O}_{22}$ & 915.6004 & $871,588,294$ & - & - & 20.314 \\
\hline Isogingerenone B & $\mathrm{C}_{22} \mathrm{H}_{26} \mathrm{O}_{6}$ & 387.3752 & $294,276,262,136$ & - & 20.79 & - \\
\hline Quercetin 3-O-glucosylrutinoside & $\mathrm{C}_{33} \mathrm{H}_{40} \mathrm{O}_{21}$ & 773.5175 & $736,425,304,209$ & 21.69 & - & 21.696 \\
\hline 6-C-Hexosyl-8-C-pentosylluteolin & $\mathrm{C}_{27} \mathrm{H}_{30} \mathrm{O}_{16}$ & 581.4343 & $425,294,150$ & - & 21.86 & - \\
\hline Kaempferol 7-O-rutinoside & $\mathrm{C}_{27} \mathrm{H}_{30} \mathrm{O}_{15}$ & 595.4149 & 409, 294, 262 & 22.19 & - & 22.18 \\
\hline Myricetin 3-(2"-galloylrhamnoside) & $\mathrm{C}_{29} \mathrm{H}_{26} \mathrm{O}_{16}$ & 631.1132 & $610,549,294$ & - & - & 22.23 \\
\hline
\end{tabular}

$\mathrm{m} / \mathrm{z}$, mass/charge; $R T$, retention time; $P R$, peaceful rest tea; $E N$, eternity tea.

(Yang et al., 2018). Nitric oxide (NO) is one of the proinflammatory mediators produced during inflammation. In the non-treated RAW 264.7 cells, the inflammatory response induced by LPS resulted in a $100 \%$ production of NO. Cells treated with tea extracts showed a reduction in nitrite accumulation in a concentration-dependent manner. Treatment with $100 \mathrm{ug} / \mathrm{ml}$ of tea extracts reduced NO production by $20 \%$ (Figure 5B). It was also observed that the anti-inflammatory activity of EN and PR extracts was not significantly different $(p<0.05)$.

Next, the chemical profile of each tea extract by LC-MS chromatograms was carried out to rationalize the findings from the in vitro assays (Figure 4A). Principal component analysis (PCA) visualized the abundance variations for the metabolites with significant differences, indicating the chemical profiles of each tea are different, $p<0.05$ (Figure 4B). Chemical analysis showed that compounds detected in the tea extracts comprised the flavonoids, catechin, and phenolic acid (Table 2). This result corroborates the high TPC values and good chemical antioxidant activity exhibited by tea extracts (Table 3). The activity of tea extracts was significantly different from that of catechin hydrate $(p<0.05)$. The generation of reactive oxygen species (ROS) and its association with oxidative stress play a crucial role in the pathogenesis of T2D. Antioxidant results indicated the ability of tea extracts to donate electrons or hydrogen to the DPPH and ABTS free radicals. Both chemical antioxidant assays have been useful for defining the chemical profiles of extracts and quality control.

Previous studies on oolong tea reported the anti-obesity and antioxidant properties of the tea (Zhang et al., 2019). Frequently, the polyphenols, particularly the tea catechins, epicatechin, epicatechin-3-gallate, epigallocatechin, and epigallocatechin-3gallate, have been associated with good antioxidant activity, thus reducing risk of diseases related to oxidative stress (Sanlier et al., 2018). Flavonoid-rich food decreases serum levels of glucose by inducing the insulin-independent $5^{\prime}$ adenosine monophosphate-activated protein kinase (AMPK) pathway. This slows the oxygen consumption of adenosine diphosphate by stimulating GLUT 4 translocation and expression in isolated mitochondria. Such mechanism is similar to that of metformin (Eid et al., 2010). Moreover, molecular studies supported that polyphenols in tea, such as catechins and gallic acid, modulate numerous pathways in the 


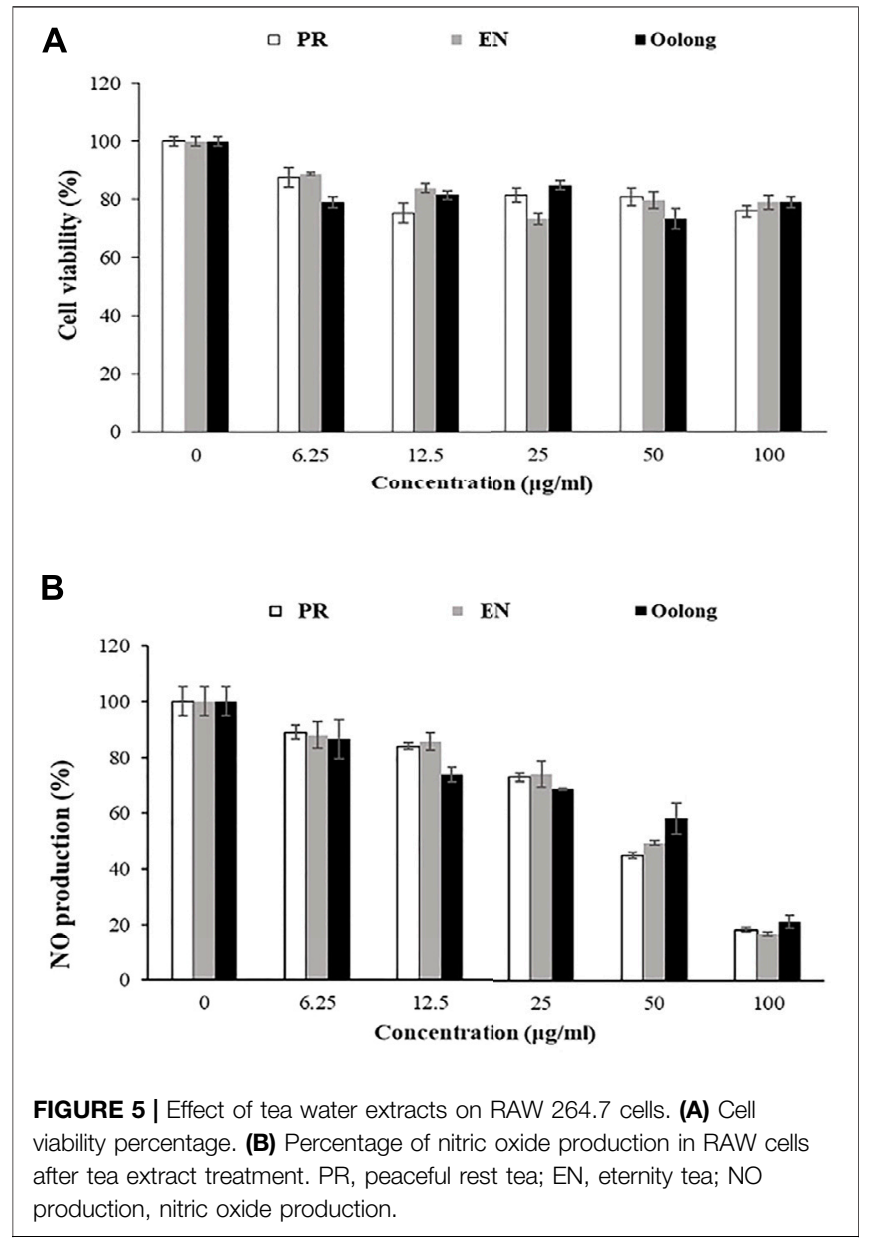

human body, including those involved in antioxidants, inflammation, apoptosis, and lipid metabolism (Shang et al., 2021).

From the chemical profiles of EN and PR, tea catechins are detected in all tea extracts. It is apparent that steaming oolong tea with Thai botanical drugs contributed to additional phytochemicals, especially flavonoids, which could be implied from the findings observed in the in vitro assays. For instance, gingerdiol and gingerol detected in EN were previously reported in ginger extracts (Kikuzaki et al., 1992), whereas piperettine I detected in PR was previously reported in Piper genus (Parmar et al., 1997). The beneficial effects of both plants on controlling blood sugar have been discussed previously. Ginger supplementation was recommended as effective adjuvant therapy for patients with T2DM (El Gayar et al., 2019), while the hypoglycemic effect of the water extract of Piper sarmentosum Roxb. on rats was also reported (Peungvicha et al., 1998).

High-molecular weight phenolic compounds such as theaflavin3-3'-digallate and thearubigin have been reported to inhibit aglucosidase (Striegel et al., 2015). However, both compounds were not detected in the tea extracts. However, the presence of quercetin 3-O-glucosylrutinoside was detected in both $\mathrm{PR}$ and oolong tea extracts could contribute to the observed $\alpha$-amylase inhibition activity. The structure-activity relationship of quercetin 3-O-glucosylrutinoside as the $\alpha$-amylase inhibitor was elucidated in a previous study (Li et al., 2018). The presence of 5-O-caffeoylquinic acid in PR, p-coumaric acid in EN, and 4-caffeoylquinic acid and 1caffeoylquinic acid in oolong tea could contribute to the antiinflammatory property of the tea extracts. Such compounds were previously observed in the Cornus officinalis var. koreana Kitam extract that attenuated the inflammatory response induced by LPS in RAW 264.7 cells (Najjar et al., 2021). Additionally, the antiinflammatory property of caffeoylquinic acids (CQAs) has also been described (Liu et al., 2020).

The antiproliferation activity of tea extracts was investigated using K562 and RAW264.7 cells. The results indicated the tea extracts were not toxic to both cells (Figures 5A,6). Evaluating tea quality, efficacy, and safety is important for the tea industry (Lin and Sun, 2020), especially to promote both safe and rational use of these special oolong teas. Finally, from the in vitro results and chemical profiles of tea extracts, this study rationalizes the consumption of oolong and special oolong teas. Nevertheless, possible contraindications and interactions when the tea is taken together with pharmaceuticals such as anti-diabetic drugs and functional foods (May and Schindler, 2016) are suggested for future study.
$\square$ PR
$\square \mathbf{E N}$
- Oolong

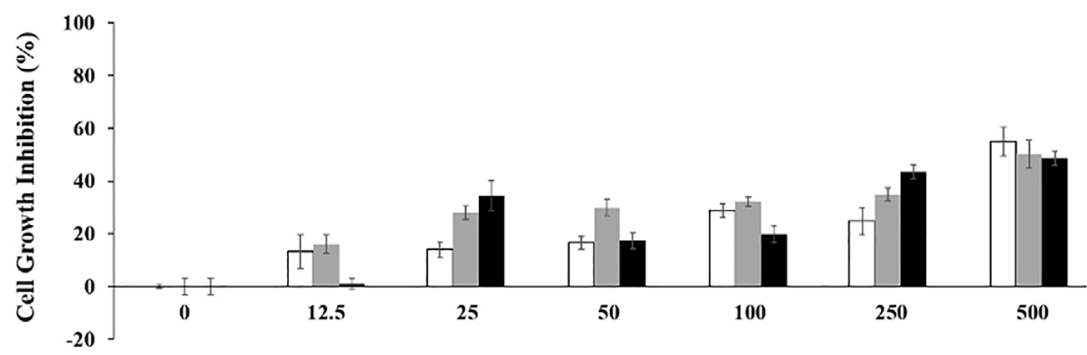

Concentration $(\mu \mathrm{g} / \mathrm{ml})$

FIGURE 6 | Anti-proliferation effect of tea extracts on K562 cells. PR, peaceful rest tea; EN, eternity tea. 


\section{CONCLUSION}

Oolong tea is already good on its own. Thai botanical drugs are steamed with the oolong tea to produce the special oolong teas, EN and PR. The extra compounds observed in the chemical profiles of PR and EN teas rationalized the good in vitro antidiabetic property of the extracts. Interestingly, among all the tea extracts, PR extracts exhibited the best activity in the in vitro assays, particularly the inhibition of glucose uptake and consumption by adipocytes and skeletal muscle. Other than tea catechins, the activities could be due to the presence of flavonoid compounds contributed by the Thai botanical drugs. Based on the results, this study suggests the potential of PR extracts to combat diabetes, cardiovascular diseases, and obesity.

\section{DATA AVAILABILITY STATEMENT}

The raw data supporting the conclusion of this article will be made available by the authors, without undue reservation.

\section{REFERENCES}

Bunkrongcheap, R., Hutadilok-Towatana, N., Noipha, K., and Wattanapiromsakul, C. (2014). Ivy Gourd (Coccinia Grandis L. Voigt) Root Suppresses Adipocyte Differentiation in 3T3-L1 Cells. Lipids Health Dis. 13, 1-10. doi:10.1186/1476-511X-13-88

Chen, D., Wang, Y., Wu, K., and Wang, X. (2018). Dual Effects of Metformin on Adipogenic Differentiation of 3T3-L1 Preadipocyte in AMPK-dependent and Independent Manners. Int. J. Mol. Sci. 19 (6), 1547. doi:10.3390/ijms19061547

Cheng, Z., Pang, T., Gu, M., Gao, A. H., Xie, C. M., Li, J. Y., et al. (2006). Berberinestimulated Glucose Uptake in L6 Myotubes Involves Both AMPK and P38 MAPK. Biochim. Biophys. Acta 1760, 1682-1689. doi:10.1016/j.bbagen.2006. 09.007

Deetae, P., Parichanon, P., Trakunleewatthana, P., and Chanseetis, C. (2012). Antioxidant and Anti-glycation Properties of Thai Herbal Teas in Comparison with Conventional Teas. Food Chem. 133, 953-959. doi:10.1016/j.foodchem. 2012.02.012

Duangyod, T., Palanuvej, C., and Ruangrungsi, N. (2015). Pharmacognostic Evaluation with Reference to Catechin Content and Antioxidant Activities of Pale Catechu in Thailand. J. Adv. Pharm. Technol. Res. 6, 97-102. doi:10. 4103/2231-4040.161505

Eid, H. M., Martineau, L. C., Saleem, A., and Muhammad, A. (2010). Stimulation of AMP-Activated Protein Kinase and Enhancement of Basal Glucose Uptake in Muscle Cells by Quercetin and Quercetin Glycosides, Active Principles of the Antidiabetic Medicinal Plant Vaccinium Vitis-Idaea. Mol. Nutr. Food Res. 54, 991-1003. doi:10.1002/mnfr.200900218

El Gayar, M. H., Aboromia, M. M., Ibrahim, N. A., and Hafiz, M. H. A. (2019). Effects of Ginger Powder Supplementation on Glycemic Status and Lipid Profile in Newly Diagnosed Obese Patients with Type 2 Diabetes Mellitus. Obes. Med. 14, 100094. doi:10.1016/j.obmed.2019.100094

Fares, M., Abedi-Valugerdi, M., Hassan, M., and Potacava, Z. (2015). DNA Damage, Lysosomal Degradation and Bcl-xL Deamidation in Doxycyclineand Minocycline-Induced Cell Death in the K562 Leukemic Cell Line. Biochem. Biophys. Res. Commun. 463, 1-7. doi:10.1016/j.bbrc.2015.05.043

He, R., Kurihara, H., and Preedy, V. R. (2013). "Oolong Tea and Weight Loss," in Tea in Health and Disease Prevention (Elsevier), 509-519. doi:10.1016/b978-012-384937-3.00042-2

Kang, D. H., Kang, O. H., Li, Z., Mun, S. H., Seo, Y. S., Kong, R., et al. (2016). Antiinflammatory Effects of Ciwujianoside C3, Extracted from the Leaves of

\section{AUTHOR CONTRIBUTIONS}

RC designed this research. NR, WJ, TD, and NP performed the in vitro and chemical experiments. TM, SR, and $\mathrm{RC}$ analyzed the data from the experiment. PP and CP collected the fresh samples. $\mathrm{RC}, \mathrm{WJ}$, and SR approved the manuscript.

\section{ACKNOWLEDGMENTS}

The authors wish to acknowledge Mae Fah Luang University, Chiang Rai, Thailand, and Doi Chang organic tea plantation in Chiang Rai, Thailand, for providing laboratory facility for the work.

\section{SUPPLEMENTARY MATERIAL}

The Supplementary Material for this article can be found online at: https://www.frontiersin.org/articles/10.3389/fphar.2022.797032/ full\#supplementary-material

Acanthopanax Henryi (Oliv.) Harms, on LPS-Stimulated RAW 264.7 Cells. Mol. Med. Rep. 14, 3749-3758. doi:10.3892/mmr.2016.5710

Kikuzaki, H., Tsai, S. M., and Nakatani, N. (1992). Gingerdiol Related Compounds from the Rhizomes of Zingiber Officinale. Phytochemistry 31 (5), 1783-1786. doi:10.1016/0031-9422(92)83147-q

Kusano, R., Ogawa, S., Matsuo, Y., Tanaka, T., Yazak,i, Y., and Kouno, I. (2011). $\alpha$-Amylase and Lipase Inhibitory Activity and Structural Characterization of acacia Bark Proanthocyanidins. J. Nat. Prod. 74, 119-128. doi:10.1021/ np100372t

Li, K., Yao, F., Xue, Q., Fan, H., Yang, L., Li, X., et al. (2018). Inhibitory Effects against $\alpha$-glucosidase and $\alpha$-amylase of the Flavonoids-Rich Extract from Scutellaria Baicalensis Shoots and Interpretation of Structure-Activity Relationship of its Eight Flavonoids by a Refined Assign-Score Method. Chem. Cent. J. 12, 1-11. doi:10.1186/s13065-018-0445-y

Lima, J. E., Moreira, N. C., and Sakamoto-Hojo, E. T. (2021). Mechanisms Underlying the Pathophysiology Type 2 Diabetes: from Risk Factors Oxidative Stress, Metabolic Dysfunction, and Hyperglycemia. Mutat. Research/Genetic Toxicol. Environ. Mutagenesis 874-875, 503437. doi:10. 1016/j.mrgentox.2021.503437

Lin, X., and Sun, D. (2020). Recent Developments in Vibrational Spectroscopic Techniques for tea Quality and Safety Analyses. Trends Food Sci. Technol. 104, 163-176. doi:10.1016/j.tifs.2020.06.009

Lin, X., Xu, Y., Pan, X., Xu, J., Ding, Y., Sun, X., et al. (2020). Global, Regional, and National burden and Trend of Diabetes in 195 Countries and Territories: an Analysis from 1990 to 2025. Sci. Rep. 10 (1), 1-11. doi:10.1038/s41598-02071908-9

Liu, W., Li, J., Zhang, X., Zu, Y., Yang, Y., Liu, W., et al. (2020). Current Advances in Naturally Occurring Caffeoylquinic Acids: Structure, Bioactivity, and Synthesis. J. Agric. Food Chem. 68, 10489-10516. doi:10.1021/acs.jafc.0c03804

Martin, M. A., Goya, L., and Ramos, S. (2017). Protective Effects of tea, Red Wine and cocoa in Diabetes. Evidences from Human Studies. Food Chem. Toxicol. 109, 302-314. doi:10.1016/j.fct.2017.09.015

May, M., and Schindler, C. (2016). Clinically and Pharmacologically Relevant Interactions of Antidiabetic Drugs. Ther. Adv. Endocrinol. Metab. 7 (2), 69-83. doi:10.1177/2042018816638050

Najjar, R. S., Akhavan, N. S., Pourafshar, S., Arjmandi, B. H., and Feresin, G. (2021). Cornus Officinalis Var. Koreana Kitam Polyphenol Extract Decreases Pro-inflammatory Markers in Lipopolysaccharide (LPS)-induced RAW 264.7 Macrophages by Reducing Akt Phosphorylation. J. Ethnopharmacology 270, 113734. doi:10.1016/j.jep.2020.113734 
Nam, T. G., Lim, T., Lee, B. H., Lim, S., Kang, H., Eom, S. H., et al. (2017). Comparison of Anti-inflammatory Effects of Flavonoid-Rich Common and Tartary Buckwheat Sprout Extracts in Lipopolysaccharide-Stimulated RAW 264.7 and Peritoneal Macrophages. Oxid. Med. Cel Longevity 2017, 1-12. doi:10.1155/2017/9658030

Parmar, V. S., Jain, S. C., Bisht, K. S., Jain, R., and Taneja, P. (1997). Phytochemistry of the Genus Piper. Phytochemistry 46 (4), 597-673. doi:10.1016/s00319422(97)00328-2

Peungvicha, P., Thirawarapan, S. S., Temsiririrkkul, R., Watanabe, H., Prasain, J. K., and Kadota, S. (1998). Hypoglycemic Effect of the Water Extract of Piper Sarmentosum in Rats. J. ethnopharmacology 60 (1), 27-32. doi:10.1016/s0378-8741(97)00127-x

Sanlier, N., Gokcen, B. B., and Altuğ, M. (2018). Tea Consumption and Disease Correlations. Trends Food Sci. Technol. 78, 95-106. doi:10.1016/j.tifs.2018.05.026

Shang, A., Li, J., Zhou, D. D., Gan, R. Y., and Li, H. B. (2021). Molecular Mechanisms Underlying Health Benefits of tea Compounds. Free Radic. Biol. Med. 172, 181-200. doi:10.1016/j.freeradbiomed.2021.06.006

Somasundaram, R., Choraria, A., Merlin, S., Narayanaswamy, K., and Vasudevan, K. (2019). A Preliminary Pilot Scale Analysis of Anti-cariogenic Activity of green tea Powder Extract Flavoured with Ginger, Cloves and Mint against Clinical Oral Pathogens. Clin. Nutr.Exp. 24, 66-71. doi:10.1016/j.yclnex.2018.12.002

Striegel, L., Kang, B., Pilkenton, S. J., Rychlik, M., and Apostolidis, E. (2015). Effect of Black tea and Black tea Pomace Polyphenols on $\alpha$-glucosidase and $\alpha$-amylase Inhibition, Relevant to Type 2 Diabetes Prevention. Front. Nutr. 2, 3. doi:10. 3389/fnut.2015.00003

Sun, C., Zhao, C., Guven, E. C., Paoli, P., Simal-Gandara, J., and Ramkumar, K. M. (2020). Dietary Polyphenols as Antidiabetic Agents: Advances and Opportunities. Food Front. 1 (1), 18-44. doi:10.1002/fft2.15

Yamamoto, N., Ueda-Wakagi, M., Sato, T., Kawasaki, K., Sawada, K., Kawabata, K., et al. (2015). Measurement of Glucose Uptake in Cultured Cells. Curr. Protoc. Pharmacol. 55, 1-26. doi:10.1002/0471141755.ph1214s71
Yang, C. S., Wang, H., and Sheridan, Z. P. (2018). Studies on Prevention of Obesity, Metabolic Syndrome, Diabetes, Cardiovascular Diseases and Cancer by tea. J. Food Drug Anal. 26, 1-13. doi:10.1016/j.jfda.2017.10.010

Zhang, H., Qi, R., and Mine, Y. (2019). The Impact of Oolong and Black tea Polyphenols on Human Health. Food Biosci. 29, 55-61. doi:10.1016/j.fbio.2019. 03.009

Zhang, L., Hu, J. J., and Du, G. H. (2008). Establishment of a Cell-Based Assay to Screen Insulin-like Hypoglycemic Drugs. Drug discoveries Ther. 2, 229-233.

Conflict of Interest: Author CP was employed by company Doi Chang Tea Co., Ltd.

The remaining authors declare that the research was conducted in the absence of any commercial or financial relationships that could be construed as a potential conflict of interest.

Publisher's Note: All claims expressed in this article are solely those of the authors and do not necessarily represent those of their affiliated organizations, or those of the publisher, the editors, and the reviewers. Any product that may be evaluated in this article, or claim that may be made by its manufacturer, is not guaranteed or endorsed by the publisher.

Copyright (C) 2022 Rujanapun, Jaidee, Duangyod, Phuneerub, Paojumroom, Maneerat, Pringpuangkeo, Ramli and Charoensup. This is an open-access article distributed under the terms of the Creative Commons Attribution License (CC BY). The use, distribution or reproduction in other forums is permitted, provided the original author(s) and the copyright owner(s) are credited and that the original publication in this journal is cited, in accordance with accepted academic practice. No use, distribution or reproduction is permitted which does not comply with these terms. 